\title{
The Impact of COVID-19 on the Environment. Short Review
}

\author{
Nagy Abdulsamee ${ }^{1 *}$, Ahmed Elkhadem ${ }^{2}$ and Passant Nagi ${ }^{3}$ \\ ${ }^{1}$ Consultant Prosthodontics and Head of Dental Biomaterials, Faculty of Oral and \\ Dental Medicine, Deraya University, Egypt \\ ${ }^{2}$ Assistant Professor of Pediatric Dentistry, Faculty of Oral and Dental Medicine and \\ Surgery, Cairo University, Egypt \\ ${ }^{3}$ Lecturer of Pediatric Dentistry, Faculty of Oral and Dental Medicine and Surgery, \\ Cairo University, Egypt \\ *Corresponding Author: Nagy Abdulsamee, Consultant Prosthodontics and Head of \\ Dental Biomaterials, Faculty of Oral and Dental Medicine, Deraya University, Egypt.
}

Received: March 22, 2021

Published: April 23, 2021

(C) All rights are reserved by Nagy

Abdulsamee., et al.

\section{Abstract}

The COVID-19 disease has recently spread as a global pandemic, posing serious threats to mankind. The World Health Organization (WHO) has issued guidelines to assist countries in reducing the spread of the virus to the general public, including the use of masks, hand hygiene, social distancing, and the shutdown of all kinds of public transportation. These circumstances resulted in a significant drop in global economic activity, but there were also indirect environmental benefits such as improved global air quality and reduced water pollution.

Because there are no clinically proven drugs or vaccines for COVID-19, face masks are currently part of a comprehensive package of prevention and control measures that can limit its spread. Face masks are typically made of non-renewable petroleum-based polymers that are non-biodegradable, dangerous to the environment and cause health problems. This review demonstrates the extensive use of the face mask and how it affects human health and the marine ecosystem positively as well as negatively. It has become a great challenge for the government sectors to impose strict regulations for the proper disposal of the masks as medical waste by the public to minimize their negative effects. Neglecting the seriousness of this issue may lead to the release of large tonnes of micro-plastics to the landfill as well as to the marine environment where mostly end-up and thereby affecting their fauna and flora population vastly.

Keywords: Face Mask; SARS-CoV-2; COVID-19; Environment; Pandemic; Regulations; Marine Environment Pollution

\section{Introduction}

SARS-CoV-2, a novel coronavirus, has caused widespread social disruption and has had serious consequences for the population's overall health. According to the World Health Organization, there are more than 47 million confirmed cases at this time, with a total of over 1,215,000 deaths (WHO). Vaccines are still being tested, and there are no effective treatments for this disease [1]. Indeed, the majority of the evidence suggests that social distancing, wearing masks, and wearing eye protection are effective at preventing transmission [2]. COVID-19 disease spread has also been found to be reduced by improved hygiene (handwashing) and the use of sanitizers $[1,3,4]$.

The outbreak of the COVID-19 pandemic has had both positive and negative environmental consequences. The benefits include a reduction in air pollution, noise pollution, clean beaches, greenhouse gas emissions, and traffic accidents. Increased waste, decreased waste recycling, unemployment, economic crises, and manufacturing demand are all negative effects. Prior to COVID-19, the world was grappling with a slew of environmental problems, 
including industrial pollution, noise pollution, water pollution, ozone layer depletion caused by greenhouse gases emitted by industry and vehicles, and excessive chemical use in agricultural industries, to name a few [5].

\section{Positive impact of COVID-19 on environment}

Reduction of environmental noise level

Noise pollution has become a major problem in major cities around the world, owing to human activities such as car traffic, high-volume speakers in commercial spaces, and sounds from various industries. Humans suffer a great deal of pain and health problems as a result of these. Noise pollution has a psychological impact on animals, particularly birds, which are particularly sensitive. The reduction in all modes of transportation and commercial operations since the government imposed the lockdown due to COVID-19 has resulted in a large drop in noise levels across the world's major cities [6].

\section{Diminishing air pollution}

Nitrogen dioxide $\left(\mathrm{NO}_{2}\right)$, carbon monoxide (CO), sulphur dioxide $\left(\mathrm{SO}_{2}\right)$, ozone $\left(\mathrm{O}_{3}\right)$, fine particulate matter (PM2.5), and coarse particulate matter (PM10) are the main air pollutants (PM10). The primary sources of these pollutants are industries and vehicle exhaust. The respiratory system, lungs, and mucus secretions are all affected by these gases. Ozone is formed when nitrogen dioxide $\left(\mathrm{NO}_{2}\right)$ reacts with air. It is emitted primarily by vehicles or industry and causes severe damage to the lungs, resulting in breathing problems. It is also a source of early childhood asthma. Particulate matter (PM) is mainly found in acid rain and causes cancer because it can easily penetrate inside the cells of the lungs. It comes in two sizes, PM10 and PM2.5, depending on their size. Pollens, moulds and dust are all part of PM10, which has a particle size of less than $10 \mathrm{~mm}$. PM2.5 is even smaller than PM10, causing health problems such as chronic obstructive pulmonary disease and lower respiratory infections, which have killed nearly three million people around the world. Ozone $\left(\mathrm{O}_{3}\right)$, formed from harmful gases emitted by vehicles or industry, is another important toxic pollutant causing severe breathing problems, lung-function reduction, triggers asthma and lung diseases. The spread of COVID-19 disease has resulted in the complete shutdown of most industries, as well as a reduction in car traffic, resulting in a significant reduction in air pollution worldwide $[7,8]$.
Cleaning the beaches

Beaches are a valuable natural resource that can be found in coastal areas. Coastal communities rely on them for land, sand, and fishing grounds to survive. Beaches are a good source of income for the government in the form of tourism, but most of them are currently heavily polluted due to anthropogenic activities. In many countries, the COVID19 lockdown has resulted in reduced movement of people in and around coastal areas, resulting in clean beaches and clear waters in the surrounding areas [9].

Negative impact of COVID-19 on environment

\section{Increased waste}

To control the spread of COVID-19 disease, many countries have imposed strict quarantines, resulting in a massive rise in organic and inorganic waste. Because the majority of essentials are now ordered online for home delivery, wastes such as food packaging and household products have resulted in an increase in both organic and inorganic waste. Aside from that, hospitals produce a significant amount of medical waste. The governments are currently in a precarious position in order to deal with the sudden increase in medical waste (gloves, masks, and disposable aprons) generated by hospitals. In these times, even the general public is aware of its proper disposal. They may still contain traces of viral contaminants if they are not properly disposed of, which can cause serious problems in the future [10]. COVID-19 medical waste is a growing threat to the aquatic environment. The demand for medical products and packaging rose dramatically during the COVID-19 pandemic. As a result, when compared to normal hospital conditions anywhere in the world, the amount of hazardous medical waste produced is huge. Medical health industries and waste management systems have already taken some precautions to control contamination and disposal of medical waste, but clearance of medical waste continues to rise, making it impossible for any government to find a solution quickly [11].

\section{Reduction in waste recycling}

Another major issue that is currently gaining traction is waste recycling. Recycling waste helps to reduce pollution, save energy, and protect natural resources. Most countries have stopped recycling waste management activities because they pose a risk to workers in recycling centers who may become infected because household or medical waste may contain trace amounts of this contaminant. The majority of countries are attempting to develop a 
solution for the proper and safe disposal of COVID-19 waste. Waste management will be difficult to handle until then $[12,13]$.

\section{Negative effects from Face masks}

Face masks are mostly made of plastic, which is highly liquid resistant and non-degradable, and may leave traces even after being thrown away. This type of hazardous plastic waste either ends up in landfills or in the oceans, wreaking havoc on the ecosystem. Health care providers wearing surgical masks that can only be worn for one day, as well as empty hand sanitizer bottles and used tissue papers, are discarded in large quantities from each hospital, potentially posing a risk to the environment as hazardous medical waste [14]. The widespread use of face masks, disposable gloves and hand sanitizers by billions of people would result in massive amounts of trash being produced around the world. As a medical waste, its impact will grow in the future, and if it is not properly handled, it could have negative consequences for the land and ocean ecosystems [15].

Elimination of the negative effects from disposable face mask, used gloves and gowns

Medical waste from hospitals, such as disposable face masks, used gloves, and gowns, must be properly handled to eliminate any remaining pathogens. Thermal procedures such as autoclaving, incineration, and plasma or microwave treatment are used in the treatment methods [16]. The majority of treatment plants are built to manage the typical flow rate and composition of medical waste. The amount of medical waste expected to be generated by hospitals during COVID-19 currently exceeds the available capacity for hazardous waste treatment. In fact, reducing capacity solely through waste compression or suppression is ineffective. It must also be ensured that pathogens found within them are eradicated entirely. After the pandemic has passed, it is likely that a large amount of treated waste will remain in the dump, which may or may not contain pathogens but will still be a significant pollutant to the environment [17].

\section{Face masks - safe recycling and energy conversion}

During the COVID-19 pandemic, a greater volume of medical waste, such as masks, gloves, and other protective equipment, was created from both infected and non-infected sources. The most important aspect in this situation is proper management of these medical wastes, which can mitigate unexpected health effects on humans and the environment. These medical wastes require: I proper identification (infected or non-infected), ii) collection and separation, iii) storage and transportation, and iv) treatment and disposal for effective management. It also necessitates certain related factors for waste management handlers, such as disinfection, employee protection, and training [18].

Countries around the world have taken a variety of steps to deal with COVID-19 waste, including double bagging with well-tied garbage bags for household waste and food containers, which are now considered dangerous due to the possibility of pathogen contamination. Separate waste collection systems are also provided for suspected or positive cases. Incineration, physical, and chemical methods are all commonly used for COVID-19 waste treatment. These methods are used in Waste Management Systems (WMS) at various stages to manage the various types of waste carried by the COVID-19 Wastes (CW) [19].

Incineration at a low or high temperature can be an effective technology for dealing with large amounts of CW, as well as a sufficient investment for disinfecting pathological and pharmaceutical CW. Though incineration technology can effectively degrade SARSCoV-2 viruses at high temperatures, it has some disadvantages, such as the release of toxins into the environment, which has a significant impact on human and animal immune systems [20]. Thermal technology is the most recent method for effectively degrading CW, and it is divided into two types: 1) Pyrolysis (which operates at high temperatures) and 2) Microwave (which operates at medium temperatures) [21].

Plastics have recently become an important application in the management of COVID-19. Recycling these plastics as an energy source is a solution to the current situation, but there are some delays in putting it into action. The purity of most recycling technologies is extremely important $[22,23]$. In the future, energy derived from recycled plastic or waste may be used to replace fossil fuels. There are only a few methods that can be used to recover energy from hazardous medical waste. The chemical content of plastics can also be recaptured by the process and used for useful purposes, as can the burning of medical waste, which can release a large amount of energy as heat [24].

\section{Conclusion}

The COVID-19 pandemic has been wreaking havoc on people all over the world for years. The virus has consumed a great deal 
of life and continues to do so. Face masks have become a necessity in today's world, and vast quantities are produced every day to meet demand. Face masks are mainly made of non-biodegradable petrochemicals as raw materials and are currently and in the future considered hazardous medical waste. The use of face masks, as well as other medical waste from hospitals and household garbage, has increased dramatically. It has become a massive task for world countries to clear this waste, which may or may not contain infectious agents. For effective management of rising medical waste, world countries must adopt a constructive methodology or system. Adequate waste recycling or conversion to other forms of energy could be an outstanding solution that any government could adopt to control the current situation. If medical wastes are not properly handled now, their impact will be magnified in the future, with potentially negative consequences for the land and ocean ecosystems. An alternative to solving the problem is to make improvised face masks using nanotechnology or biomaterials, which should have the same or better effectiveness than conventional ones and be entirely biodegradable so as not to damage the terrestrial and marine ecosystems [25].

\section{Conflicts of Interest}

The authors declare no conflict of interest.

\section{Bibliography}

1. Eikenberry SE., et al. "To mask or not to mask: modeling the potential for face mask use by the general public to curtail the COVID-19 pandemic". Infectious Disease Modelling 5 (2020): 293-308.

2. Chu DK., et al. "Physical distancing, face masks, and eye protection to prevent person-to-person transmission of SARS-CoV-2 and COVID-19: a systematic review and metaanalysis". Lancet 395 (2020): 1973-1987.

3. Cheng VC., et al. "The role of community-wide wearing of face mask for control of coronavirus disease 2019 (COVID-19) epidemic due to SARS-CoV-2". Journal of Infection 81 (2020): 107114.

4. WHO, Coronavirus Disease (COVID-19) Advice for the Public: When and How to Use Masks (2020).

5. Saadat S., et al. "Environmental perspective of COVID-19". Science of the Total Environment 728 (2020): 138870.
6. Zambrano-Monserrate MA and Ruano MA. "Does environmental noise affect housing rental prices in developing countries?" Evidence from Ecuador Land Use Pol 87 (2019): 104059.

7. $\operatorname{ESA}(2020)$.

8. $\quad$ ESA (2020).

9. MA Zambrano-Monserrate and MA Ruano L. "Indirect effects of COVID-19 on the environment Sci". Total Environment 728 (2020): 138813.

10. 2020 .

11. KF Ho., et al. "Chuang Medical mask versus cotton mask for preventing respiratory droplet transmission in micro environments". Sciences of the Total Environment 735 (2020): 139510.

12. 2020 .

13. Dharmaraj S., et al. "COVID-19 pandemic face mask waste: A blooming threat to the marine environment". Chemosphere 272 (2021): 129601.

14. Phan TL and Ching CTS. "A reusable mask for coronavirus disease 2019 (COVID-19)". Archives of Medical Research 51.5 (2020): 455-457.

15. HellewellJ S., et al. "Feasibility of controlling COVID-19 outbreaks by isolation of cases and contacts". The Lancet Global Health 8.4 (2020): 488-496.

16. Liu HC., et al. "Evaluating healthcare waste treatment technologies using a hybrid multi-criteria decision-making model Renew". Sustainable Energy Reviews 41 (2015): 932-942.

17. Yu H., et al. "Reverse logistics network design for effective management of medical waste in epidemic outbreaks: insights from the coronavirus disease 2019 (COVID-19) outbreak in Wuhan (China)". International Journal of Environmental Research and Public Health 17 (2020): 1770.

18. Bourouiba L. "Turbulent gas clouds and respiratory pathogen emissions - potential implications for reducing transmission of COVID-19". The Journal of the American Medical Association 323.18 (2020): 1837-1838.

19. Ilyas S., et al. "Disinfection technology and strategies for COVID-19 hospital and bio-medical waste management". Sciences of the Total Environment 749 (2020): 41652. 
20. Wang J., et al. "Disinfection technology of hospital wates and wastewater: suggestions for disinfection strategy during coronavirus disease 2019 (COVID-19) pandemic in China". Environ Pollution 262 (2020): 114665.

21. S Papari and K Hawboldt. "A review on condensing system for biomass pyrolysis process Fuel Process". Technologies 180 (2018): 1-13.

22. SY Lee., et al. "Show Waste to bioenergy: a review on the recent conversion technologies". BMC Energy 1 (2019): 4.

23. Cheng SY., et al. "Incorporating biowaste into circular bioeconomy: A critical review of current trend and scaling up feasibility". Environmental Technology and Innovation 19 (2020): 101034.

24. Hong J., et al. "Life-cycle environmental and economic assessment of medical waste treatment". Journal of Cleaner Production 174 (2018): 65-73.

25. Dharmaraj S., et al. "The COVID-19 pandemic face mask waste: A blooming threat to the marine environment". Chemosphere 272 (2021): 129601.

\section{Assets from publication with us}

- Prompt Acknowledgement after receiving the article

- Thorough Double blinded peer review

- Rapid Publication

- Issue of Publication Certificate

- High visibility of your Published work

Website: www.actascientific.com/ Submit Article: www.actascientific.com/submission.php Email us: editor@actascientific.com Contact us: +919182824667 